\title{
Myb Oncogene Protein
}

National Cancer Institute

\section{Source}

National Cancer Institute. Myb Oncogene Protein. NCI Thesaurus. Code C17320.

Human MYB Oncogene Protein is a product of a mutated variant (Oncogene MYB) of MYB Gene, which encodes 6 alternative isoforms of 640 aa 72-kDa nuclear c-MYB protein, a DNA-binding transcriptional activator critical for hematopoietic progenitor cell proliferation and differentiation. MYB contains $3 \mathrm{~N}$-terminal MYB-like DNA-binding domains that specifically recog nize YAAC[GT]G, a central transcriptional activation domain and a C-terminal transcriptional repression domain. MYB may interact with HIPK2 and NLK; phosphorylation by NLK on multiple sites may induce proteasomal degradation. Ubiquitination may be mediated by SIAH1. MYB Oncogene Protein disrupts normal cell function. 